\title{
A U.S. survey of pre-operative carbohydrate-containing beverage use in colorectal enhanced recovery after surgery (ERAS) programs
}

Sunitha M. Singh ${ }^{1 *}$ D, Asha Liverpool ${ }^{1}$, Jamie L. Romeiser ${ }^{1}$, Joshua D. Miller², Julie Thacker ${ }^{3}$, Tong J. Gan ${ }^{1}$ and Elliott Bennett-Guerrero ${ }^{1}$

\begin{abstract}
Background: Carbohydrate-containing drinks (CCD) are administered preoperatively in most enhanced recovery after surgery (ERAS) programs. It is not known which types of CCDs are used, e.g., simple vs. complex carbohydrate, and if the choice of drink differs in patients with diabetes.

Methods: A national survey was performed to characterize the use of preoperative CCDs within the context of adult colorectal ERAS programs. The survey had questions regarding the use of preoperative CCDs, the types of beverages used, and the timing of beverage administration. The survey was administered electronically to members of the American Society for Enhanced Recovery (ASER) and manually to participants at the 2018 Perioperative Quality and Enhanced Recovery Conference in San Francisco, CA.

Results: Responses were received from 78 unique hospitals with a colorectal ERAS program of which 68 (87.2\%) reported administering a preoperative drink. Of these, $98.5 \%, 80.9 \%$, and $60.3 \%$ of hospitals administered a beverage to patients without diabetes, patients with diabetes not taking insulin, and patients with diabetes taking insulin, respectively. Surprisingly, one third of programs that administered a beverage to patients with diabetes used a simple carbohydrate drink.
\end{abstract}

Conclusions: This survey finds a high use of CHO-containing beverages in colorectal ERAS programs. More than half of all programs administer a CHO-containing beverage to patients with diabetes, and surprisingly, there is significant use of simple carbohydrate beverages in patients with diabetes receiving insulin.

Keywords: Enhanced recovery, ERAS, Pre-operative, Carbohydrate-containing beverage, Insulin, Diabetes

\footnotetext{
* Correspondence: Sunitha.singh@stonybrookmedicine.edu

'Department of Anesthesiology, Stony Brook University Medical Center, 101 Nicholls Road, Health Science Center, L-4, 060, Stony Brook, NY 11794-8480, USA

Full list of author information is available at the end of the article
}

(C) The Author(s). 2021 Open Access This article is licensed under a Creative Commons Attribution 4.0 International License, which permits use, sharing, adaptation, distribution and reproduction in any medium or format, as long as you give appropriate credit to the original author(s) and the source, provide a link to the Creative Commons licence, and indicate if changes were made. The images or other third party material in this article are included in the article's Creative Commons licence, unless indicated otherwise in a credit line to the material. If material is not included in the article's Creative Commons licence and your intended use is not permitted by statutory regulation or exceeds the permitted use, you will need to obtain permission directly from the copyright holder. To view a copy of this licence, visit http://creativecommons.org/licenses/by/4.0/ The Creative Commons Public Domain Dedication waiver (http://creativecommons.org/publicdomain/zero/1.0/) applies to the data made available in this article, unless otherwise stated in a credit line to the data. 


\section{Background}

Enhanced recovery after surgery (ERAS) programs are evidence-based, multidisciplinary, surgical care pathways, which have become widespread over the past 2 decades (Pogatschnik \& Steiger, 2015; Ackerman et al., 2020). ERAS programs were initially implemented in elective colorectal surgeries, and their use within this service line has been well studied (Carey \& Hogan, 2021; Burden et al., 2012). This research has contributed to expansion of ERAS programs to additional surgical service lines (e.g., thoracic, cardiac, gynecology and orthopedic surgeries) (Ackerman et al., 2020; Desiderio et al., 2018). The effectiveness of ERAS programs, comprised of approximately 20 elements, is likely due to its ability to standardize care for patients undergoing elective surgery (Carey \& Hogan, 2021; Desiderio et al., 2018; Gramlich et al., 2017). Despite the now ubiquitous nature of ERAS programs, research regarding individual elements is limited.

In most ERAS programs, preoperative carbohydratecontaining drinks (CCD) are a common component. CCDs have been shown to improve the endocrine and metabolic response to surgical stress as well as reduce pre-operative discomfort, e.g., thirst, hunger, anxiety (Pogatschnik \& Steiger, 2015; Ackerman et al., 2020; Hausel et al., 2001; Gustafsson et al., 2008; Talutis et al., 2020; Tall \& Nygren, 2020; Loodin \& Hommel, 2020; Çakar et al., 2017). Preoperative CCDs include simple carbohydrates, e.g., apple juice, or complex carbohydrates, e.g., maltodextrin, for which there are multiple commercial preparations. Little is known about which preoperative CCDs are more frequently used in ERAS programs across United States (U.S.) hospitals. This is particularly relevant to patients with diabetes, where the use of preoperative CCDs might impact perioperative glycaemia, potentially leading to delay or case cancelation (Cua et al., 2021). Moreover, if surgery occurs, the dysglycemia could be detrimental (American Society of Anesthesiologists Committee, 2011). Alternatively, it would be unfortunate if CCDs are withheld from patients with diabetes in order to avoid hyperglycemia when in fact their use is proven safe and effective, since allowing patients with diabetes to avoid preoperative fasting may be particularly beneficial (Ackerman et al., 2020; Gustafsson et al., 2008; Talutis et al., 2020; Tall \& Nygren, 2020).

Therefore, we conducted a survey to characterize the use and type of pre-op CCDs drinks in adult colorectal ERAS programs across the U.S. By identifying how ERAS pathways are using pre-operative drinks, we aim to inform the ERAS community on current practices regarding the use of preoperative CCDs.

\section{Methods}

\section{Data collection}

Institutional review board (IRB) approval was obtained from the Stony Brook University IRB. The brief 9- question survey, available as Additional file 1, asked questions regarding the use of preoperative CCDs, including the types of beverages used, the timing of beverage administration, and institutional demographics. The survey underwent a multidisciplinary review during the design and test phase and was programmed with branching logic to help minimize "missing data." The survey was circulated electronically using the Qualtrics (Provo, UT) online software to members of the American Society for Enhanced Recovery between September and November 2018. The survey was also administered to participants at the October 2018 Perioperative Quality and Enhanced Recovery Conference in San Francisco, CA.

\section{Statistical analysis}

Analyses were performed at the institutional level. To not over represent, i.e., double-count, institutions in the study, only one response per institution was chosen. The first, most completed survey response submitted was used. Duplicate responses from institutions, surveys with unknown institutions, and non-U.S. site responses were excluded from the analysis. Responses that were missing overall beverage data (i.e., respondents did not indicate if they provided beverages by patient type) were excluded from that patient type analysis. Additionally, some responses that were missing or listed multiple drinks in the "other" category were unable to be assigned a single type of carbohydrate category (i.e., simple or complex) and were therefore excluded from the type of carbohydrate by patient type analyses. Differences in dependent proportion tests were used to compare beverage use and beverage carbohydrate $(\mathrm{CHO})$ types between patients with diabetes taking insulin and patients without diabetes (Wild \& Seber, 1993).

\section{Results}

Approximately 292 surveys were distributed ( 192 electronically and 100 in-person), and 148 completed surveys were received; thus, the estimated response rate was $50.7 \%$. The completed surveys represented 88 unique U.S. hospitals, 78 (88.6\%) of which had colorectal ERAS programs. Sensitivity analyses confirmed that responses where similar for electronically and manually administered surveys. Respondents identified as anesthesiologists (44.3\%), ERAS coordinator (19.3\%), surgeon (14.8\%), nurse (10.2\%), certified registered nurse anesthetist (3.4\%), other (3.4\%), nurse practitioner (2.3\%), and dietitian (2.3\%).

Of the 78 adult colorectal ERAS programs, 68 (87.2\%) hospitals reported that they administer a CCD prior to colorectal surgery. Of these 68 colorectal programs using a preoperative CCD, $98.5 \%$ administered a beverage to patients without diabetes, $79.7 \%$ administered a beverage 
Table 1 Preoperative CCD use in colorectal ERAS programs

\begin{tabular}{|c|c|c|c|c|c|c|c|}
\hline \multirow{2}{*}{$\begin{array}{l}\text { Colorectal ERAS } \\
\text { programs using a } \\
\text { preoperative CCD ( } n \\
=68)\end{array}$} & \multicolumn{2}{|c|}{$\begin{array}{l}\text { Given to patients without } \\
\text { diabetes }\end{array}$} & \multicolumn{2}{|c|}{$\begin{array}{l}\text { Given to patients with diabetes not } \\
\text { receiving insulin }\end{array}$} & \multicolumn{2}{|c|}{$\begin{array}{l}\text { Given to patients with diabetes } \\
\text { receiving insulin }\end{array}$} & \multirow{2}{*}{$\begin{array}{l}\text { Difference } \\
\text { in } \\
\text { dependent } \\
\text { proportions } \\
\text { test }\end{array}$} \\
\hline & $n(\%)$ & $95 \% \mathrm{Cl}$ & $n(\%)$ & $95 \% \mathrm{Cl}$ & $n(\%)$ & $95 \% \mathrm{Cl}$ & \\
\hline Use of any beverage & $67(98.5)$ & $92.1-100$ & $55(80.9)$ & $69.8-89.4$ & $42(60.3)$ & $47.7-72$ & $p<0.05$ \\
\hline \multicolumn{8}{|l|}{ Type of carbohydrate } \\
\hline Simple & $23(37.7)$ & $25.5-49.9$ & $17(33.3)$ & $20.8-47.9$ & $13(34.2)$ & $19.6-51.4$ & $P=\mathrm{ns}$ \\
\hline Complex & $38(62.3)$ & $49-74.4$ & $34(66.7)$ & $52.1-79.2$ & $25(65.8)$ & $48.7-80.4$ & $P=\mathrm{ns}$ \\
\hline
\end{tabular}

to patients with diabetes not taking insulin, and $60.9 \%$ administered a beverage to patients with diabetes taking insulin $(p<0.05)$. Table 1 shows use of CCDs in these subgroups. The most common simple sugar CCDs used in all populations was Gatorade ${ }^{\circ}$, followed by apple juice. The most common complex sugar CCDs used in all populations were ClearFast $^{\bullet}$ and Ensure Pre-surgery ${ }^{\circledR}$; see Table 2. Ninety-seven percent of programs reported administration of the CCD on the morning of surgery, and half of these hospitals also gave it the night before.

Surprisingly, 34\% of the institutions that administered CCDs to patients who take insulin to manage their diabetes used a simple $\mathrm{CHO}$ beverage. As shown in Table 1 across these patient subgroups, the proportion of simple $\mathrm{CHO}$ and complex $\mathrm{CHO}$ use was evenly distributed (within 5 percentage points). The type of CCD used was not statistically different between patients without diabetes vs. patients with diabetes taking insulin $(p=\mathrm{NS})$. The majority of respondents (84\%) reported using the same preoperative CCD beverage in other, i.e., noncolorectal, ERAS pathways at their hospital.

\section{Discussion}

Studies have shown that traditional preoperative fasting places patients in a catabolic state, thereby increasing their risk of adverse effects related to the surgery. Preoperative CCD use mitigates this risk by maintaining patients in an anabolic state, allowing for better glycemic control and muscle preservation (Pogatschnik \& Steiger, 2015; Ackerman et al., 2020; Talutis et al., 2020; Tall \& Nygren, 2020). Neither the ERAS Society USA, the American Society for Enhanced Recovery (ASER), or the American Diabetes Association have promulgated specific guidelines on the use of preoperative CCDs. In 2013, Gustaffson et al. reviewed the current evidence and strongly recommended the routine use of preoperative CCDs but only weakly recommended administering these beverages to patients with diabetes (Gustafsson et al., 2012). Other than the suggestion that fluids contain preferably at least $45 \mathrm{~g}$ of complex $\mathrm{CHO}$, there is no clear consensus on which CCDs to use (Ackerman et al., 2020; Thiele et al., 2016). Thus, the use of preoperative CCDs among U.S. ERAS programs and among patients with diabetes is unclear.

We were surprised to find that the ERAS programs we surveyed did not appear to vary in the types of beverage they provided to patients with or without diabetes. This is different from the practice at our center (Stony Brook), where, based on the theoretical risk of perioperative hyperglycemia, we do not administer a CCD (simple or complex) to patients with known diabetes.

Our study has several potential limitations. The goal of this survey was not to assess the impact of CCDs on perioperative glycemia or any other outcomes, e.g., postoperative nausea and vomiting; therefore, we cannot comment on what is the best practice in this regard.

Table 2 Specific preoperative CCD use reported in colorectal ERAS programs

\begin{tabular}{llll}
\hline $\begin{array}{l}\text { Colorectal ERAS } \\
\text { programs using } \\
\text { a pre-op CCD }(n \\
=68)\end{array}$ & $\begin{array}{l}\text { Given to patients without } \\
\text { diabetes } \\
n(\%)\end{array}$ & $\begin{array}{l}\text { Given to patients with diabetes not } \\
\text { receiving insulin } \\
n(\%)\end{array}$ & $\begin{array}{l}\text { Given to patients with diabetes receiving } \\
\text { insulin } \\
n(\%)\end{array}$ \\
\hline $\begin{array}{l}\text { Clear-Fast }{ }^{\ominus} \\
\begin{array}{l}\text { Ensure Pre- } \\
\text { Surgery }\end{array}\end{array}$ & $18(29.5)$ & $16(31.4)$ & $12(31.6)$ \\
Gatorade & $17(27.9)$ & $16(31.4)$ & $11(29)$ \\
Apple juice & $6(9.8)$ & $11(21.6)$ & $10(26.3)$ \\
Other & $4(6.6)^{1}$ & $5(9.8)$ & $2(5.3)$ \\
\hline
\end{tabular}

${ }^{1}$ Patients without diabetes-other (4) includes 1 Gatorade ${ }^{\oplus}$ zero, 2 Glycemic Endothelial Drink ${ }^{\mathrm{TM}}$ (G.E.D.), and 1 Ensure ${ }^{\oplus}$ clear

${ }^{2}$ Patients with diabetes not receiving insulin-other (3) includes 1 Gatorade ${ }^{\oplus}$ zero and 2 G.E.D. ${ }^{\mathrm{TM}}$

${ }^{3}$ Patients with diabetes receiving insulin—other (3) includes 1 Gatorade ${ }^{\circledast}$ zero, 1 Gatorade ${ }^{\circledast}$ prime, and 1 G.E.D. ${ }^{\mathrm{TM}}$ 
Additional study is needed on the potential impact of administration of CCDs to patients with diabetes prior to surgery. The survey underwent a multidisciplinary review prior to distribution. Though the survey was administered electronically and manually, possibly leading to inconsistencies, we found that the results were similar for electronic and manual survey responses. This is not surprising as we would not expect these results to differ substantially based on how the survey was delivered. While multiple fail safes were implemented (e.g., branching logic) to minimize missing data or multiple answers, we did have a few responses that needed to be excluded from analyses. Overall missing data was rare (only 2/67 surveys did not specify a beverage type for any of the patients with diabetes/without diabetes groups). However, a handful of respondents who specified "other" as the beverage type did not further explain the type or listed multiple types of beverages that were both simple and complex. This led to the exclusion of this data for the carbohydrate analyses. Finally, similar to most surveys, we asked respondents to report on when the CCD was administered instead of prospectively obtaining source documents/logs showing exact dates/times of beverage administration. Therefore, it is possible that their responses do not accurately reflect what really happens to patients at their site.

Whether or not the timing and frequency of administration of $\mathrm{CHO}$-containing beverages matters also requires more research. The American Society of Anesthesiologists (ASA) guidelines currently recommend allowing clear liquids up to 2 hours prior to elective procedures (Hausel et al., 2001). The majority of our survey respondents reported giving CCDs the morning of surgery, with half of these also administering it the night before.

\section{Conclusion}

In summary, our study found that both simple sugar and complex sugar CCDs are commonly used within colorectal ERAS pathways. Surprisingly, we found substantial use of these CCDs, especially simple sugar CCDs, even in patients with diabetes who take insulin. Additional studies are needed to inform the ERAS community whether this variability in practice is deleterious.

\section{Abbreviations}

ASA: American Society of Anesthesiologists; ASER: American Society for Enhanced Recovery; CCD: Carbohydrate-containing drink;

$\mathrm{CHO}$ : Carbohydrate; ERAS: Enhanced recovery after surgery; IRB: Institutional review board

\section{Supplementary Information}

The online version contains supplementary material available at https://doi. org/10.1186/s13741-021-00187-3

Additional file 1:

\section{Acknowledgements}

The authors would like to thank the Department of Anesthesiology, Stony Brook University Medical Center, USA, and the American Society for Enhanced Recovery for their support in the conduct of this survey.

\section{Authors' contributions}

SS contributed to the design, execution, drafting and revision of the work. AL contributed to the acquisition of data and drafting and revision of the work. JR contributed to the acquisition, analysis, and interpretation of data and revision of the work. JM contributed to the drafting and revision of the work. JT contributed to the drafting and revision of the work. TG contributed to the drafting and revision of the work. EBG contributed to the design, execution, drafting and revision of the work. All authors read and approved the final manuscript.

\section{Funding}

This work was supported by internal resources from Stony Brook University Medical Center, Department of Anesthesiology. This research did not receive any specific grant from funding agencies in the public, commercial, or notfor-profit sectors.

\section{Availability of data and materials}

The datasets used are not available.

\section{Declarations}

Ethics approval and consent to participate

This research study was approved by the Stony Brook Institutional Review Board, reference number 1314361-1.

\section{Consent for publication}

Not applicable

\section{Competing interests}

$\mathrm{SS}, \mathrm{AL}, \mathrm{JR}, \mathrm{JM}, \mathrm{TG}$, and EBG have no competing interests. JT is on the speakers' bureau and advisory board of Abbott (receives honorarium or travel reimbursement) and the advisory board of Nestle (no money paid).

\section{Author details}

${ }^{1}$ Department of Anesthesiology, Stony Brook University Medical Center, 101 Nicholls Road, Health Science Center, L-4, 060, Stony Brook, NY 11794-8480, USA. ${ }^{2}$ Department of Medicine/Endocrinology, Stony Brook University Medical Center, 101 Nicolls Road, Health Science Center, L-4, 060, Stony Brook, NY 11794-8480, USA. ${ }^{3}$ Department of Surgery, Duke University Medical Center, 10 Duke Medicine Circle, Durham, NC 27710-1000, USA.

Received: 14 May 2020 Accepted: 16 April 2021

Published online: 28 May 2021

\section{References}

Pogatschnik C, Steiger E. Review of Preoperative Carbohydrate Loading. Nutr Clin Pract. 2015;30(5):660-4. https://doi.org/10.1177/0884533615594013.

American Society of Anesthesiologists Committee. Practice guidelines for preoperative fasting and the use of pharmacologic agents to reduce the risk of pulmonary aspiration: application to healthy patients undergoing elective procedures: an updated report by the American Society of Anesthesiologists Committee on Standards and Practice Parameters. Anesthesiology. 2011; 114(3):495-511. https://doi.org/10.1097/ALN.0b013e3181fcbfd9.

Burden S, Todd C, Hill J, Lal S. Pre-operative nutrition support in patients undergoing gastrointestinal surgery. Cochrane Database Syst Rev. 2012;11: CD008879.

Çakar E, Yilmaz E, Çakar E, Baydur H. The effect of preoperative oral carbohydrate solution intake on patient comfort: a randomized controlled study. J Perianesth Nurs. 2017;32(6):589-99. https://doi.org/10.1016/j.jopan.2016.03. 008

Carey S, Hogan S. Failure in systems and culture: barriers that prevent implementation of evidence-based fasting times for patients in the acute care setting. J Parenter Enter Nutri. 2021. https://doi.org/10.1002/jpen.1961.

Cua S, Humeidan M, Beal EW, Brethauer S, Pervo V, Papio J, et al. The effect of an enhanced recovery protocol on colorectal surgery patients with diabetes. J Surg Res. 2021;257:153-60. https://doi.org/10.1016/j.jss.2020.07.041. 
Desiderio J, Stewart CL, Sun V, Melstrom L, Warner S, Lee B, et al. Enhanced recovery after surgery for gastric cancer patients improves clinical outcomes at a US cancer center. J Gastric Cancer. 2018;18(3):230-41. https://doi.org/10. 5230/jgc.2018.18.e24

Gramlich LM, Sheppard CE, Wasylak T, Gilmour LE, Ljungqvist O, BasualdoHammond C, et al. Implementation of Enhanced Recovery After Surgery: a strategy to transform surgical care across a health system. Implement Sci. 2017;12(1):67. https://doi.org/10.1186/s13012-017-0597-5.

Gustafsson UO, Nygren J, Thorell A, Soop M, Hellstrom PM, Ljungqvist O, et al. Pre-operative carbohydrate loading may be used in type 2 diabetes patients. Acta Anaesthesiol Scand. 2008;52(7):946-51. https://doi.org/10.1111/j.13996576.2008.01599.x.

Gustafsson UO, Scott MJ, Schwenk W, Demartines N, Roulin D, Francis N, et al. Guidelines for perioperative care in elective colonic surgery: Enhanced Recovery After Surgery (ERAS ${ }^{\oplus}$ ) Society Recommendations. World I Surg. 2012;37(2):259-84. https://doi.org/10.1007/s00268-012-1772-0.

Hausel J, Nygren J, Lagerkranser M, Hellström PM, Hammarqvist F, Almström C, et al. A carbohydrate-rich drink reduces preoperative discomfort in elective surgery patients. Anesth Analg. 2001;93(5):1344-50. https://doi.org/10.1097/ 00000539-200111000-00063.

Loodin $\AA$, Hommel A. The effects of preoperative oral carbohydrate drinks on energy intake and postoperative complications after hip fracture surgery: a pilot study. Int J Orthop Trauma Nurs. 2020:100834. https://doi.org/10.1016/j. ijotn.2020.100834.

Pogatschnik C, Steiger E. Review of preoperative carbohydrate loading. Nutr Clin Pract. 2015;30(5):660-4. https://doi.org/10.1177/0884533615594013.

Tall J, Nygren J. (2020) Preoperative fasting and carbohydrate treatment. In: Ljungqvist $\mathrm{O}$, Francis $\mathrm{N}$, Urman R, editors. Enhanced recovery after surgery. Cham: Springer; 2020. https://doi.org/10.1007/978-3-030-33443-7_4

Talutis SD, Lee SY, Cheng D, Rosenkranz P, Alexanian SM, McAneny D. The impact of preoperative carbohydrate loading on patients with type II diabetes in an enhanced recovery after surgery protocol. Am J Surg. 2020; 220(4):999-1003. https://doi.org/10.1016/j.amjsurg.2020.03.032.

Thiele RH, Raghunathan K, Brudney CS, Lobo DN, Martin D, Senagore A, et al. American Society for Enhanced Recovery (ASER) and Perioperative Quality Initiative (POQI) joint consensus statement on perioperative fluid management within an enhanced recovery pathway for colorectal surgery Perioper Med. 2016;5(1):24. https://doi.org/10.1186/s13741-016-0049-9.

Wild CJ, Seber GAF. Comparing two proportions from the same survey. Am Stat. 1993:47(3):178-81. https://doi.org/10.1080/00031305.1993.10475972.

\section{Publisher's Note}

Springer Nature remains neutral with regard to jurisdictional claims in published maps and institutional affiliations.

Ready to submit your research? Choose BMC and benefit from:

- fast, convenient online submission

- thorough peer review by experienced researchers in your field

- rapid publication on acceptance

- support for research data, including large and complex data types

- gold Open Access which fosters wider collaboration and increased citations

- maximum visibility for your research: over $100 \mathrm{M}$ website views per year

At BMC, research is always in progress.

Learn more biomedcentral.com/submissions 